\title{
The effects of the gut microflora and dietary fibre on energy utilization by the chick
}

\author{
By S. N. HEGDE,* B. A. ROLLS AND MARIE E. COATES \\ National Institute for Research in Dairying, Shinfield, Reading RG2 9AT
}

(Received 5 May 1981-Accepted 26 January 1982)

\begin{abstract}
1. Groups of adult colostimized chickens were given diets with and without dietary fibre in the form of bagasse or wheat straw. The fibrous materials were analysed for their contents of cellulose, hemicellulose and lignin. The digestible energies (DE) and metabolizable energies (ME) of these diets were measured by a balance method.

2. Groups of germ-free and conventional chicks aged 4 weeks were given diets with and without penicillin or with and without graded levels of wheat straw as a source of fibre and the ME of these diets were determined.

3. The incorporation of the forms of dietary fibre tested reduced the DE and the ME of the diets in adult conventional chickens and the ME in young germ-free and conventional chicks. Both DE and ME were reduced in proportions that suggested that the dietary fibre present was acting largely as an inactive diluent of the dietary energy and was not affecting the absorption of other nutrients. In the young germ-free and conventional chicks, there was a linear relationship between the proportion of wheat straw in one diet and the reduction in $\mathrm{ME}$.

4. Dietary penicillin did not alter the ME of the diet in either the germ-free or the conventional environments.

5. The reduction of ME with incorporation of wheat straw was less in conventional than in germ-free chicks. It is suggested that this may be due to the ability of chicks with a gut flora to obtain a small amount of energy from wheat straw.
\end{abstract}

Until recently dietary fibre has not been considered a necessary ingredient in the food of simple-stomached animals. Non-ruminant species are not thought to obtain nutrients directly from fibre although those with caeca may derive energy from fatty acids produced by fermentation. Relatively little is known of the effects of dietary fibre on the digestion and absorption of other nutrients. It has been shown that wheat bran accelerates intestinal transport in man (Payler et al. 1975) and the suggestion was made that fibre may act as a restriction on energy intake and mitigate against obesity (Heaton, 1973). In view of the increased rate of passage induced by dietary fibre, its inclusion in a diet may be expected to decrease the availability of nutrients by reducing the period of exposure of the food to digestive enzymes and the absorptive surfaces. Moreover, mechanical damage by the abrasive fibre could also affect nutrient uptake. It is, however, possible that the hydrophilic properties of fibre could lead to increased digesta volume and easier access by the enzyme.

The aim of the work reported here was to investigate the effects of incorporating fibre in the diet on energy digestion and absorption in the chick. In view of the known ability of bacteria to digest cellulose, consideration was also given to a possible interaction between gut flora and the fibre in the diet.

\section{MATERIALS AND METHODS}

\section{Chicks}

Rhode Island Red $\times$ Light Sussex cross chicks were used throughout; they were hatched from eggs from a specified pathogen-free flock maintained at this Institute. For Expt 1 the birds were given a practical chick diet until they were colostomized at 12-16 weeks of age. They were then housed individually in large wire-mesh cages and maintained on the practical diet until the experiment started. In Expt 2 the eggs were incubated for $18 \mathrm{~d}$ in a commercial incubator and then disinfected by spraying with peracetic acid solution

\footnotetext{
* Present address: Department of Physiology, Mangalore University, Mangalore - 574152, India.
} 
(Harrison, 1969). Half the eggs were transferred to Gustafsson stainless steel isolators (Gustafsson, 1959) and maintained germ-free and the remaining eggs were replaced in the incubator. After hatching, the germ-free chickens were housed in groups of four in stainless steel cages with mesh floors within the isolators while their conventional counterparts were kept similarly housed in rooms where the environment was maintained to match that within the isolators. The continued microbial sterility of the birds within the isolators was checked at intervals (Fuller, 1968). In both experiments male and female birds were distributed evenly among the experimental groups as far as possible and all were allowed free access to food and water throughout.

\section{Diets}

The practical-type basal diet contained $(\mathrm{g} / \mathrm{kg})$ : maize meal 378 , barley meal 345 , dried grass meal 30 , bone meal 15 , limestone flour 10 , sodium chloride 6.72 , vitamin supplement 5 , maize oil 10, $\mathrm{MnSO}_{4} \cdot 4 \mathrm{H}_{2} \mathrm{O} 0 \cdot 28$. Cholecalciferol was dissolved in the maize oil to provide $16 \mu \mathrm{g} / \mathrm{kg}$ diet. Rovimix A500 (Roche Products, 318 High Street North, Dunstable LU6 1BG) was added to supply $2 \mathrm{mg}$ retinol $/ \mathrm{kg}$. The vitamin supplement provided $(\mathrm{mg} / \mathrm{kg}$ ) riboflavin $7 \cdot 7$, nicotinic acid 55 , biotin $0 \cdot 22$, pteroylmonoglutamic acid $0 \cdot 83$, thiamin hydrochloride $3 \cdot 3$, pyridoxine hydrochloride $4 \cdot 4$, calcium pathothenate $16 \cdot 5$, cyanocobala$\min 0.02$.

The low-residue basal diet of semi-purified ingredients in Expt 1 contained $(\mathrm{g} / \mathrm{kg})$ maize starch $602 \cdot 5$, casein 180 , gelatin 100 , salt mixture 60 , L-cystine 3 , choline chloride $1 \cdot 5$, myo-inositol 1, vitamin supplement 2 , maize oil 50 . The salt mixture supplied $(\mathrm{mg} / \mathrm{kg})$ $\mathrm{CaCO}_{3} 17100, \mathrm{KH}_{2} \mathrm{PO}_{4} 13300, \mathrm{CaHPO}_{4} .2 \mathrm{H}_{2} \mathrm{O} 17100, \mathrm{NaCl} 8670, \mathrm{MnSO}_{4} .4 \mathrm{H}_{2} \mathrm{O} 270, \mathrm{KI}$ $37, \mathrm{CuSO}_{4} \cdot 5 \mathrm{H}_{2} \mathrm{O} 160, \mathrm{ZnSO}_{4} \cdot 7 \mathrm{H}_{2} \mathrm{O} 130, \mathrm{MgSO}_{4} \cdot \mathrm{H}_{2} \mathrm{O} 2670, \mathrm{FeSO}_{4} \cdot 7 \mathrm{H}_{2} \mathrm{O} 670$. Fatsoluble vitamins dissolved in the maize oil provided $(\mathrm{mg} / \mathrm{kg})$ : cholecalciferol 0.04 , menaphthone 4, $\alpha$-tocopheryl acetate 10. Rovimix A500 was added to supply $5 \mathrm{mg}$ retinol $/ \mathrm{kg}$. The vitamin supplement provided $(\mathrm{mg} / \mathrm{kg})$ : biotin $0 \cdot 4$, pteroylmonoglutamic acid $1 \cdot 5$, thiamin hydrochloride 3 , pyridoxine hydrochloride 4 , riboflavin 6 , calcium pantothenate 15 , nicotinic acid 40 , cyanocobalamin 0.02 . When the low-residue basal diet was made up for Expt 2 the vitamin supplements were increased fourfold to compensate for possible destruction during sterilization.

The sources of dietary fibre were finely-powdered bagasse (the fibrous by-product of the extraction of sugar from sugar cane (Sacharrum officinarum)) and milled wheat straw. They were incorporated in the diets at the expense of maize starch. Procaine penicillin was added to the basal diet to provide $250 \mathrm{mg}$ penicillin $/ \mathrm{kg}$. All diets were granulated and those required to be sterile for Expt 2 were packed in plastic bags, evacuated, sealed and sterilized by gamma radiation at $5 \mathrm{Mrad}$. In Expt 2 both germ-free and conventional chicks were given the sterilized diets.

\section{Experimental}

Expt I. In this work measurements were made of both digestible (DE) and metabolizable energy (ME), so it was necessary to use colostomized birds in order that urine and faeces might be collected separately. Chickens of 12-16 weeks were colostomized by the method of Okumura (1976) and when recovery was complete the experimental diets were offered ad lib. For each pair of diets, as far as possible, half the available colostomized chickens were given each diet for the first feeding period, then for the second feeding period each bird was given the other diet of the pair, so that during every trial all birds ate both diets. The feeding periods lasted for $7 \mathrm{~d}$, a $4 \mathrm{~d}$ adaptation period followed by a $3 \mathrm{~d}$ collection period. During the collection period the food was again freely available and spillage and food consumption were determined daily. Twice daily, faeces and urine were collected and stored at $-20^{\circ}$ until analysis. 
Three pairs of diets were tested: the low-residue diet with and without $20 \mathrm{~g}$ bagasse $/ \mathrm{kg}$ and both the practical and the low-residue diet with and without $50 \mathrm{~g}$ wheat straw $/ \mathrm{kg}$. The fibre concentration was increased after the bagasse in an attempt to increase the small effect found with this fibre inclusion.

Expt 2. A preliminary test with adult colostomized chickens gave results suggesting that incorporating penicillin in the practical diet affected its DE and ME. The possibility that the intestinal flora might alter the utilization of dietary energy was investigated in a series of experiments in which ME was measured in groups of germ-free and conventional chicks.

The sterilized experimental diets were given from hatching; and at 4 weeks of age food intake was determined and a total collection of excreta was made over a $3 \mathrm{~d}$ period. The excreta was kept at $-20^{\circ}$ until analysis. Expt 2a compared the practical diet with and without penicillin. Expt $2 \mathrm{~b}$ was carried out using the low-residue diet with and without $50 \mathrm{~g}$ wheat straw $/ \mathrm{kg}$ to investigate the possibility, suggested by the results of Expt 2a, that there might be a difference in the effect of fibrous material in the germ-free and conventional environments. Encouraging but inconclusive results from Expt $2 \mathrm{~b}$ led to a further test (Expt $2 c)$ in which a range of four diets based on the low-residue diet and containing $0,100,200$ and $300 \mathrm{~g}$ wheat straw $/ \mathrm{kg}$ was given. Four groups of four chicks received each experimental treatment in both Expts $2 \mathrm{a}$ and $2 \mathrm{~b}$ and six groups of four in Expt $2 \mathrm{c}$.

\section{Analysis}

Nitrogen and energy. The faeces and the excreta were freeze-dried and weighed. Samples of diet, dried faeces and dried excreta and of urine were taken for estimation of $\mathrm{N}$ by the micro-Kjeldahl method. The urine was homogenized before sampling to ensure even distribution of the uric acid crystals. Energies were determined by bomb calorimetry in a Gallenkamp Automatic Adiabatic Bomb Calorimeter Type CB-100 (A. Gallenkamp \& Co. Ltd, Technico House, Christopher Street, London EC2P 2ER). For urine, the energy sample was freeze-dried in a standard, weighed plastic bag and the whole was compressed into a pellet and ignited in the bomb calorimeter. So that corrections might be made, numbers of empty, weighed plastic bags were also ignited. DE and ME were calculated according to the procedure of Hill \& Anderson (1958).

Fibre analysis. The fractionation procedure outlined by Southgate (1969) was slightly modified and was as follows. Representative samples of 4-5 g were extracted three times with hot methanol in water $(850 \mathrm{ml} / \mathrm{l})$, washed in three changes of diethyl ether, dried for $10 \mathrm{~min}$ at $90^{\circ}$, cooled to room temperature and weighed. The methanol-insoluble material was then finely ground to pass a 36 mesh seive and was frozen at $-20^{\circ}$ for $24 \mathrm{~h}$ and thawed to disrupt the cell walls as recommended by McConnell \& Eastwood (1974). Portions weighing $0.6-0.8 \mathrm{~g}$ were taken for analysis of cellulose, hemicellulose and lignin. Each portion was heated with $10 \mathrm{ml}$ distilled water in a boiling water-bath for $10 \mathrm{~min}$ to gelatinize the starch. After cooling, $0.6 \mathrm{ml} 2 \mathrm{M}$-acetate buffer of $\mathrm{pH} 4 \cdot 6$ was added followed by $3 \mathrm{ml}$ Agidex (amyloglucosidase; BDH Chemicals Ltd, Poole; $100 \mathrm{~g} / \mathrm{l}$ ) and the tubes were incubated overnight at $37^{\circ}$ for the removal of starch. The hemicellulose fraction was extracted with sulphuric acid $(50 \mathrm{ml} / \mathrm{l})$ in a boiling water-bath for $2.5 \mathrm{~h}$. The insoluble residue was then further extracted in sulphuric acid $(720 \mathrm{~g} / \mathrm{kg})$ for $36 \mathrm{~h}$ at $4^{\circ}$. The residue insoluble in the stronger acid was taken to be lignin and was weighed. Correction for inorganic ash was not made as preliminary analysis indicated an ash content of less than $5 \mathrm{~g} / \mathrm{kg}$. The extracts containing the hemicellulose and cellulose fractions were diluted to appropriate volumes with saturated benzoic acid. The hexoses were measured using the anthrone-thiourea procedure of Roe (1955) with glucose as the standard. For the estimation of pentoses the modified method of Albaum \& Umbriet (1947) was followed, using the ferric chloride-hydrochloric acid reagent suggested by D. A. T. Southgate (personal 
Table 1. Dietary fibre: the unavailable carbohydrate and lignin contents $(\mathrm{g} / \mathrm{kg}$ of air-dried material) of bagasse, wheat straw and the practical chick diet*

\begin{tabular}{|c|c|c|c|c|c|c|c|c|c|c|}
\hline & \multicolumn{4}{|c|}{ Hemicelluloses } & \multicolumn{4}{|c|}{ Celluloses } & \multirow[b]{2}{*}{ Lignin } & \multirow{2}{*}{$\begin{array}{c}\text { Total } \\
\text { dietary } \\
\text { fibre }\end{array}$} \\
\hline & Hexoses & Pentoses & $\begin{array}{l}\text { Uronic } \\
\text { acids }\end{array}$ & Total & Hexoses & Pentoses & $\begin{array}{l}\text { Uronic } \\
\text { acids }\end{array}$ & Total & & \\
\hline Bagasse & $36 \cdot 0$ & $165 \cdot 9$ & $25 \cdot 9$ & $227 \cdot 8$ & $321 \cdot 1$ & $46 \cdot 7$ & $60 \cdot 6$ & $433 \cdot 8$ & $161 \cdot 8$ & $823 \cdot 3$ \\
\hline Wheat straw & $44 \cdot 5$ & $179 \cdot 2$ & $33 \cdot 2$ & 256.9 & $316 \cdot 5$ & $43 \cdot 6$ & $63 \cdot 9$ & $425 \cdot 5$ & $123 \cdot 7$ & $804 \cdot 5$ \\
\hline Practical diet & 56.6 & $44 \cdot 3$ & $15 \cdot 5$ & 116.4 & $20 \cdot 2$ & $2 \cdot 3$ & 9.9 & $32 \cdot 3$ & $11 \cdot 7$ & $160 \cdot 4$ \\
\hline
\end{tabular}

* For details of diet composition, see p. 74.

Table 2. Expt 1. Digestible (DE) and metabolizable energy (ME) as proportions of the gross energy of pairs of diets* with and without dietary fibre measured with adult colostomized chickens aged 4-6 months

\begin{tabular}{|c|c|c|c|c|}
\hline Diet & $\begin{array}{l}\text { No. of } \\
\text { chickens }\end{array}$ & $\begin{array}{l}\text { Food intake } \\
\qquad(\mathrm{g} / 3 \mathrm{~d})\end{array}$ & DE & ME \\
\hline Low residue & 3 & 251 & 0.958 & 0.879 \\
\hline Low-residue with bagasse & $4 \dagger$ & 258 & 0.933 & 0.849 \\
\hline $\begin{array}{l}\text { Statistical significance of difference } \\
\text { between diets; } P< \\
\text { SED }(2 \mathrm{df})\end{array}$ & - & - & $\begin{array}{l}0.05 \\
0.0057\end{array}$ & $\begin{array}{l}\text { NS } \\
0.0082\end{array}$ \\
\hline $\begin{array}{l}\text { Low residue } \\
\text { Low-residue with wheat straw }(50 \mathrm{~g} / \mathrm{kg})\end{array}$ & $\begin{array}{l}5 \dagger \\
5 \dagger\end{array}$ & $\begin{array}{l}267 \\
172\end{array}$ & $\begin{array}{l}0.961 \\
0.903\end{array}$ & $\begin{array}{l}0 \cdot 873 \\
0 \cdot 822\end{array}$ \\
\hline $\begin{array}{l}\text { Statistical significance of difference } \\
\text { between diets; } P< \\
\text { SED }(3 \mathrm{df})\end{array}$ & - & - & $\begin{array}{l}0.01 \\
0.0066\end{array}$ & $\begin{array}{l}0.05 \\
0.0135\end{array}$ \\
\hline $\begin{array}{l}\text { Practical } \\
\text { Practical with wheat straw }(50 \mathrm{~g} / \mathrm{kg})\end{array}$ & $\begin{array}{l}3 \\
3\end{array}$ & $\begin{array}{l}253 \\
178\end{array}$ & $\begin{array}{l}0 \cdot 810 \\
0 \cdot 779\end{array}$ & $\begin{array}{l}0 \cdot 743 \\
0 \cdot 709\end{array}$ \\
\hline $\begin{array}{l}\text { Statistical significance of difference } \\
\text { between diets; } P< \\
\text { SED }(2 \mathrm{df})\end{array}$ & - & - & $\begin{array}{c}\text { NS } \\
0 \cdot 0353\end{array}$ & $\begin{array}{l}\text { NS } \\
0.0275\end{array}$ \\
\hline
\end{tabular}

NS, not significant $(P>0.05)$; SED, standard error of the difference based on the 'diet $\times$ chicken' interaction mean square.

* For details see p. 74.

$\dagger$ One chicken did not receive the other diet.

communication). The values were corrected for hexose interference. The carbazole method of Bitter \& Muir (1962) was adopted for measuring uronic acids, with glucuronolactone as the standard.

Statistical analysis. Differences between treatments were investigated in both experiments by analysis of variance. In Expt 1 the significances of the differences between diets were assessed in the analyses using the chickens $x$ diets interaction mean square. In Expts $2 \mathrm{a}$ and $2 b$ the sources of variation, diets, environments and diets $x$ environments, were assessed using the variation between replicate groups. In Expt 2c the same sources were assessed using the interaction between treatments and stages of the Expt.

\section{RESULTS}

Fibre analysis. Despite their different origins, the bagasse and wheat straw had similar gross compositions and both contained approximately $800 \mathrm{~g}$ dietary fibre $/ \mathrm{kg}$, defined to consist of cellulose, hemicellulose and lignin (Table 1). 
Expt 1. The results obtained with adult colostomized chickens are presented in Table 2. In general, the addition (at the expense of maize starch) of a source of dietary fibre reduced both the ME and DE of the diets tested. These reductions were significant in the experiments with the low-residue basal diet, but did not reach significance in the test with the practical diet, in which the variability between chickens was higher. The numbers of determinations were uneven in the bagasse experiment because of the malfunction of the artificial anus in one chicken after it had been given only one of the diets. The proportional reduction caused by the incorporation of the fibre was approximately the same for DE and ME.

Expt 2. In a preliminary test carried out with only two adult colostomized chickens, the incorporation of procaine penicillin into the practical diet increased the DE $(0.821-0.874)$ and the ME $(0.757-0.808)$. The first test (Expt $2 a)$, which was designed to test whether this effect could be observed in growing birds, failed to confirm this preliminary indication: there was no significant difference in ME with or without penicillin in either germ-free or conventional environments (Table 3). However, the value for ME was significantly higher $(P<0.05)$ in the conventional environment.

The second trial (Expt 2b) was carried out to test whether this result might be due to an interaction between the gut flora and the fibrous material present in the practical diet. Measurements were made of ME with the low-residue diet with or without $50 \mathrm{~g}$ wheat straw $/ \mathrm{kg}$ diet in both environments. As in Expt 1, incorporation of the fibre resulted in a significant $(P<0.05)$ reduction in ME, but the difference between environments and the interaction between diets and environments were not significant (Table 3). Nevertheless, in the germ-free environment, for the diet with fibre the value for ME was lower than that found for conventional chicks, a result which was sufficiently encouraging to justify a more extensive trial with a range of fibre concentrations.

In the final trial (Expt 2c) ME measurements were made in both environments with the low-residue diet alone and with three different concentrations of wheat straw. Once again, there was no difference between values in the two environments for the low-residue diet given alone (Table 4). The incorporation of increasing proportions of fibre progressively lowered the ME value and, moreover, this reduction was greater in the germ-free than in the conventional environment. Analysis of variance showed significant effects of environment $(P<0.01)$ and diet $(P<0.001)$. The interaction between environment and diet just failed to be significant $(0.05<P<0 \cdot 10)$ and the deviations from linearity were not significant. The linear effect of the incorporation of wheat straw averaged over environments was significant $(P<0.001)$, and this linearity is expressed in the following equations relating ME $(y)$ to the proportion of wheat straw in the diet $(x)$ :

$$
\begin{aligned}
\text { for germ-free chicks: } y=0.811-c .92 x, \\
\text { for conventional chicks: } y=0.809-0.77 x \text {. }
\end{aligned}
$$

The reduction in ME as the proportion of wheat straw in the diet increased was greater in germ-free than in conventional chicks $(P<0.05)$ : the slopes in the previously mentioned equations were significantly different.

A further manipulation was carried out. Similar equations to those previously mentioned relating $\mathrm{ME}(\mathrm{MJ} / \mathrm{kg}$ air-dried diet; $y)$ to the proportion of wheat straw $(x)$ were also calculated:

$$
\begin{aligned}
\text { for germ-free chicks: } y=14 \cdot 335-16.21 x, \\
\text { for conventional chicks: } y=14.307-13.57 x .
\end{aligned}
$$

If it is assumed (see DISCUSSION) that the differences in ME of diets containing fibre measured in germ-free and conventional environments arose from the different abilities of the two groups of chicks to extract energy from the fibrous component of the diet, it is possible 
S. N. Hegde, B. A. Rolls and Marie E. Coates

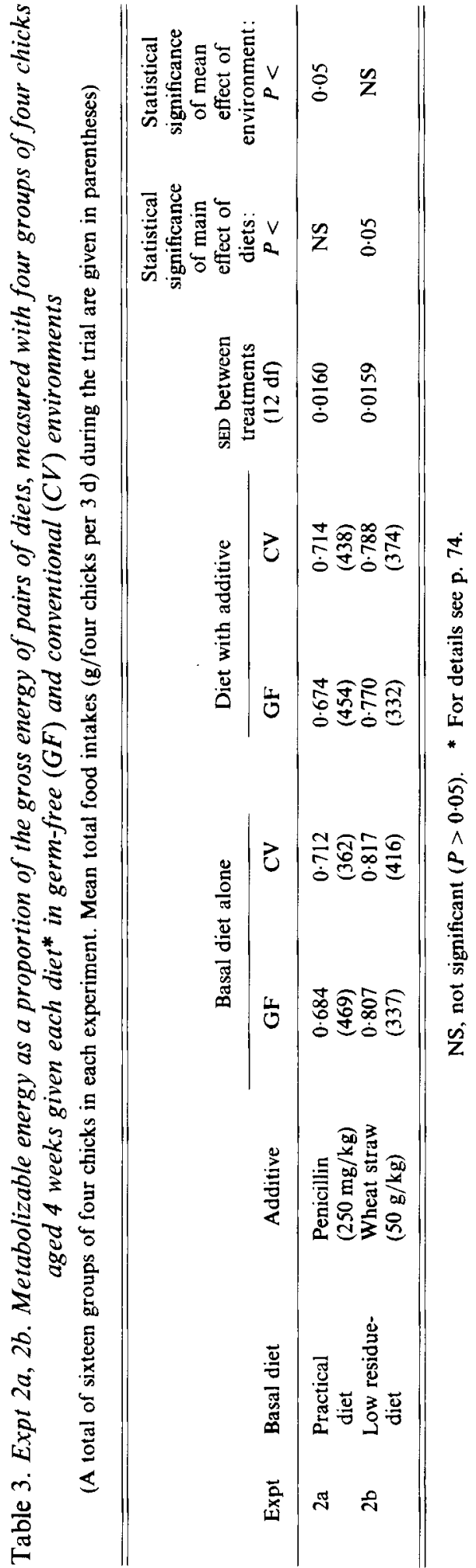


Table 4. Expt 2c. Metabolizable energy as a proportion of the gross energy of diets made up from a low-residue basal diet and containing, $0,100,200$ or $300 \mathrm{~g}$ wheat straw/kg diet measured by giving each diet* to six groups of four chicks aged 4 weeks in a germ-free $(G F)$ and conventional ( $C V$ ) environment

(The experiment was carried out in three equal stages, giving a total of forty-eight groups of four chicks in all. Mean total food intakes ( $\mathrm{g} /$ four chicks per $3 \mathrm{~d}$ ) during the trials are given in parentheses)

\begin{tabular}{ccccc}
\hline \hline $\begin{array}{c}\text { Wheat straw in diet } \\
(\mathrm{g} / \mathrm{kg})\end{array}$ & 0 & 100 & 200 & 300 \\
\hline $\mathrm{GF}$ & 0.811 & 0.714 & 0.633 & 0.532 \\
& $(450)$ & $(410)$ & $(439)$ & $(473)$ \\
$\mathrm{CV}$ & 0.811 & 0.724 & 0.665 & 0.573 \\
& $(410)$ & $(439)$ & $(468)$ & $(434)$
\end{tabular}

SED between means ( $14 \mathrm{df}) 0 \cdot 0116$.

SED standard error of the difference based on the 'treatment $\times$ stage' interaction mean square.

* For details see p. 74

(using a published value of the ME for poultry for the maize starch that the wheat straw replaced of $16.30 \mathrm{MJ} / \mathrm{kg}$ (Brown, 1964)) to calculate notional values for the ME of wheat straw; for conventional birds the value was $2 \cdot 73 \pm 0.95 \mathrm{MJ} / \mathrm{kg}$ whereas for germ-free chicks the value was $0.09 \mathrm{MJ} / \mathrm{kg}$, which was not significant.

\section{DISCUSSION}

Although there has been some discussion on the merits of $\mathrm{N}$ correction in ME determinations we have followed the view of Leeson et al. (1977) that $\mathrm{N}$ correction is essential and that correction to zero $\mathrm{N}$ retention is to be preferred.

The ME values reported here are of apparent ME since no corrections were made for endogenous energy losses. The work of Sibbald (1975) suggests that, although true ME is a constant, apparent ME varies with level of feed intake, particularly at low feed consumptions. If a reduction in ME is associated with a lower feed intake in a particular trial it is not always possible to be sure that a variable other than food intake is responsible for the difference. Inspection of the mean food intakes (Tables 2-4) and the intakes of individual groups reveals no consistent pattern: lower MEs were as likely to be associated with higher as with lower than average food consumptions. It seems probable, therefore, that these estimations have been carried out at a sufficient level of food consumption for ME to be relatively insensitive to changes in food intake and that it is justifiable to consider other causes for differences in ME.

The results obtained with adult chickens in Expt 1 are perhaps surprising. The known effect of dietary fibre in accelerating intestinal passage (e.g. Payler et al. 1975) and the possibility of mechanical damage to the absorptive surface suggest that the incorporation of fibre in a diet might lead to a reduction in the digestibility of nutrients. Although the hydrophilic properties of fibre may, by increasing digesta volume, facilitate enzyme attack, this is unlikely to be important in a feed as readily digested as the low-residue diet. The results of these experiments suggest that the fibre was acting merely as a diluent: for example, wheat straw at $50 \mathrm{~g} / \mathrm{kg}$ provided dietary fibre at approximately $40 \mathrm{~g} / \mathrm{kg}$ and the reductions found in DE and ME were approximately 30-50 parts in 1000. Much the same reduction was found in Expt 2 . It can be argued that the chick, with its relatively short gut, may react differently from the rat or man to fibre in its diet, and in support of this view 
Savory \& Gentle (1976) failed to demonstrate any effect of fibre on the rate of passage of digesta in the quail.

The results of Expts $2 \mathrm{~b}$ and $2 \mathrm{c}$ support the suggestions that in the chick the incorporation of dietary fibre reduces the $\mathrm{ME}$ of a diet to an extent suggesting that the fibre acts as a relatively inactive diluent with little or no effect on the rest of the diet. Further, that the effect on ME is linear at least up to $300 \mathrm{~g}$ fibre $/ \mathrm{kg}$ diet.

The differences in ME in germ-free and conventional environments of diets containing fibre found in Expts $2 a$ and $2 c$ (and to some extent in 2b) suggest either that the presence of a gut flora enabled the birds to extract useful energy from the fibrous component of the diet or that an interaction between fibre and gut flora somehow rendered the other nutrients of the diet more susceptible to digestible attack. For reasons stated previously, the former hypothesis seems more tenable in the instance of the well-digested, low-residue diet.

The calculation of ME made on this basis (see Results) suggests that germ-free chicks are able to extract little or no energy from the wheat straw (ME $0.09 \mathrm{MJ} / \mathrm{kg}$ ) whereas conventional chicks are able to utilize a non-zero, if small, amount of energy (ME $2.73 \mathrm{MJ} / \mathrm{kg}$ ) from this component of the diet.

The following general conclusions can be drawn. The forms of dietary fibre tested in this work appear to act essentially as inert diluents of the other nutrients in the chick, having no other effect on their digestion and utilization. These results lend no support to the suggestion that the improved growth generally observed in germ-free chicks as compared with their conventional counterparts might be related to an improved utilization of dietary energy. Finally, the presence of the gut flora apparently enables the chick to extract a small but definite amount of energy from the fibrous component of the diet despite its inert nature.

The authors are grateful to Mrs S. Thurston for technical assistance and to Dr D. Hewitt for help with the statistical interpretation. They thank Mr J. P. Fordham for care of the germ-free chicks and Miss M. Tyler for care of the conventional birds. S.N.H. was the recipient of a Commonwealth Scholarship for post-doctoral research.

\section{REFERENCES}

Albaum, H. G. \& Umbriet, M. W. (1947). J. biol. Chem. 167, 369.

Bitter, T. \& Muir, H. M. (1962). Analyt. Biochem. 4, 330.

Brown, W. O. (1964). High Energy Diets for Poultry. London: U.S. Food Grains Council.

Fuller, R. (1968). In The Germ-free Animal in Research, p. 37 [M. E. Coates, editor]. London: Academic Press. Gustafsson, B. E. (1959). Ann. N.Y. Acad. Sci. 78, 17.

Harrison, G. F. (1969). Lab. Anim. 3, 51.

Heaton, K. W. (1973). Lancet ii, 1416.

Hill, F. W. \& Anderson, D. L. (1958). J. Nutr. 64, 587.

Leeson, S., Boorman, K. N., Lewis, D. \& Shrimpton, D. H. (1977). Br. Poult. Sci. 18, 373.

McConnell, A. A. \& Eastwood, M. A. (1974). J. Sci. Fd Agric. 25, 1451.

Okumura, J. (1976). Br. Poult. Sci. 17, 547.

Payler, D. K., Pomare, E. W., Heaton, K. W. \& Harvey, R. F. (1975). Gut 16, 209.

Roe, R. H. (1955). J. biol. Chem. 212, 335.

Savory, C. J. \& Gentle, M. J. (1976). Br. Poultry Sci. 17, 561.

Sibbald, I. R. (1975), Poult. Sci. 54, 1990.

Southgate, D. A. T. (1969). J. Sci. Fd Agric. 20, 331. 